\title{
An approach to finding an integral characteristic of ionospheric and lightning activity from WWLLN observational data
}

\author{
N. G. Kudryavtsev ${ }^{1}$, D. V. Kudin ${ }^{1,2}$, and E. O. Uchaikin ${ }^{1}$ \\ Received 11 May 2018; accepted 25 June 2018; published 22 November 2018.
}

An integral parameter for estimating the ionospheric and lightning activity (Ionosphere \& Lightning Intention Index, I\&LII) has been proposed. This parameter is derived from the spectrogram of a signal recorded in the frequency range of 9 to $11 \mathrm{kHz}$ at a World Wide Lightning Location Network (WWLLN) station in real time. KEYWORDS: Lightning location; Earth-ionosphere waveguide; ionosphere; lightning; atmospheric electricity; instrumentation/sensors.

Citation: Kudryavtsev, N. G., D. V. Kudin, and E. O. Uchaikin (2018), An approach to finding an integral characteristic of ionospheric and lightning activity from WWLLN observational data, Russ. J. Earth. Sci., 18, ES6003, doi:10.2205/2018ES000637.

\section{Introduction}

Lightning activity research makes it possible to find approaches to solving a variety of economic and scientific problems ranging from the location of high-voltage power transmission lines and forest fire sources to the refinement of the model of global electric circuit of the surface atmospheric layer.

The methods used for lightning activity research are predominantly passive methods [Kozlov and Mullayarov, 2004; i.e., they fix electromagnetic (less frequently, sound) signals generated by lightning discharges (atmospherics). The simplest of these methods can fix and calculate the number of atmospheric discharges generated by a lightning event over some time interval. These methods belong to the class of lightning counters [Friese, 2004 , 2009. The rest of methods for analyzing lightning activity are commonly identified as lightning direction finders, with their technologies being generally

\footnotetext{
${ }^{1}$ Gorno-Altaisk State University, Gorno-Altaisk, Russia

${ }^{2}$ Geophysical Center of the Russian Academy of Sciences, Moscow, Russia
}

Copyright 2018 by the Geophysical Center RAS. http://rjes.wdcb.ru/doi/2018ES000637-res.html divided into two classes: single-point and multipoint direction finders [Dowden et al., 2002 Kozlov et al., 2010. The single-point methods for estimating the atmospherics parameters use directional loop antennas (an antenna system normally consists of two magnetic and one whip electric antenna, which are located in perpendicular planes) and a special-purpose software and hardware system. Using the amplitude characteristics of a signal, one can estimate the distance to the lightning discharge, and using the difference in the characteristics of the signal received by mutually perpendicular magnetic antennas, one can find the direction of the lightning event that generated the atmospherics. Normally, these methods operate in the near field (up to $300-400 \mathrm{~km}$ ) and have a rather low accuracy in finding the coordinates of lightning discharges. The multi-point methods can use both electric (whip) and magnetic (loop) antennas; they differ substantially from single-point direction finding methods by the use of high-precision synchronization and specific signal processing algorithms for estimating the time required for a wave packet to propagate from the original point of the atmospherics to several network stations with known coordinates that recorded the required signal [Hutchins et al.,2012a. 


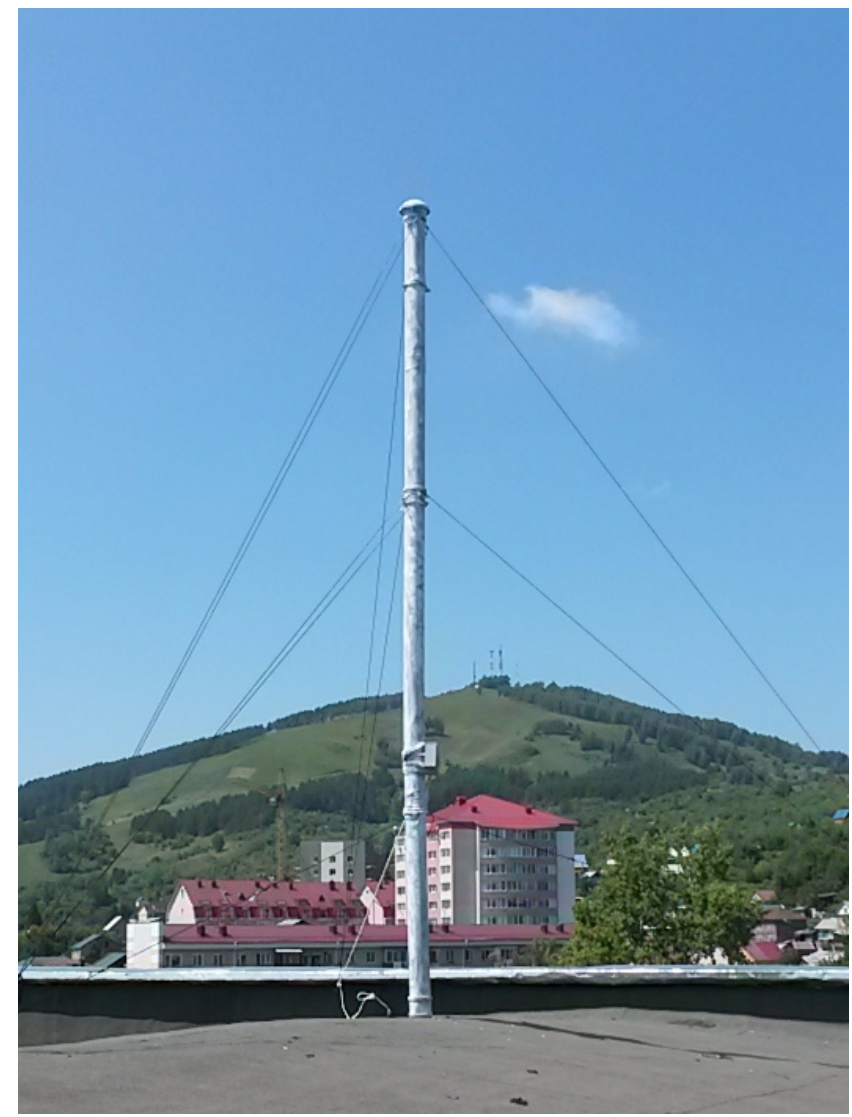

Figure 1. Antenna system of the WWLLN station Togagasu.

Historically, the latter of the above-mentioned classes has been developed and implemented partly through studies on the propagation of VLF radio signals in the Earth-ionosphere waveguide to provide VLF radio communications in the LF and VLF ranges. This range of electromagnetic waves is attractive for radio communication because the signal from a source can be received at almost any point of the Earth, both on its surface and at some underwater depth. In addition, it is very difficult to "mask" out this signal with the help of mobile electronic warfare tools. However, the main problem for researchers of this range of radio waves was that very strong radio emission sources were needed. Because of this, the researchers began to use atmospherics (lightning discharges) as "complementary" sources of strong radio emission in the VLF band.

Since the main energy of electromagnetic radiation of a lightning discharge can be attributed to the frequency band close to $11 \mathrm{kHz}$, this signal, like that of a VLF radio station, propagates to a distance of more than a thousand kilometers rereflecting from the "walls" of the Earth-ionosphere waveguide; therefore, the "audibility" of distant lightnings (the amplitude of the signal received at the observation point) as well as the audibility of VLF radio stations located several thousand kilometers away depend essentially on both the signal source power (in our case, the lightning "power") and the state of the waveguide and ionosphere as one of its "walls" along the entire "path" between the source (lightning) and the receiver (observational point). It is the extent of this dependence that is addressed in this paper exemplified by the integral parameter introduced by us.

\section{Research Methods}

As mentioned above, large-scale observation of lightnings requires rather sophisticated hardware, software, and computing resources. Therefore, to derive some new parameters characterizing the lightning activity, we have focused on the use of old proven and reliable technologies, rather than on the development of new systems. Here, it would be desirable to use data that can be freely distributed.

Our initial technologies were those used for observations in the World Wide Lightning Location Network (WWLLN), which makes it possible to collect data on lightning activity for the whole Earth. This choice was caused not only by the availability of measurement results, but also by the fact that our results can be simply verified against the results obtained by other researchers.

One of the WWLLN stations (internally codenamed as Togagasu) that was taken by us to obtain the results described in this paper is located in the main building of Gorno-Altaysk State Uni-

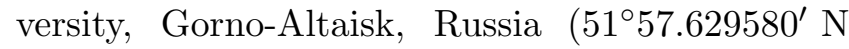
and $85^{\circ} 58.215447^{\prime} \mathrm{E}$ ). This is an antenna system (Figure 1) with an electric whip antenna, a lowfrequency amplifier with a band-pass filter, and a differential amplifier for signal transmission to a long line, connected through a matching transformer with a channel of the PC sound card for galvanic isolation. A 1-pps signal from the GPS receiver goes into the same sound card through the second channel.

The system operates with VLF signals of up to 
$20 \mathrm{kHz}$. To assess the quality of the antenna system and the "purity" of the electromagnetic background in the observational range at the WWLLN station startup, the developers use a spectrogram generated at the operating WWLLN station in real time in certain time intervals (minute, ten minutes, etc.). Here, the spectrogram contains data on the first fifteen seconds of the chosen time interval in the range from 0 to $24 \mathrm{KHz}$. To obtain an integral index of lightning activity, we chose a "minute" spectrogram and a frequency band of 9 to $11 \mathrm{kHz}$. There were several reasons for this choice. First, the frequencies of $10-11 \mathrm{kHz}$ account for the major portion of the energy spectrum of an atmospheric lightning discharge. Second, the frequency range of $12 \mathrm{kHz}$ and above includes signals of various navigation and command stations, which can introduce regular noises into the given signal.

The required integral parameter is calculated in the following way. For all frequencies between 9 and $11 \mathrm{kHz}$, the sums of "amplitudes" are found for each of the color channels of the original spectrogram (the names of the components correspond to the RGB color model: $\mathrm{R}$ component, $\mathrm{G}$ component, and $\mathrm{B}$ component) and then the average value is calculated. The result is reduced to the scale $(0: 100)$ :

$$
I_{r, g, b}=\frac{\sum_{i=1}^{h_{c}} \sum_{j=1}^{w_{c}} p_{r, g, b}^{i, j}}{h_{c} w_{c}\left(2^{n}-1\right)} \times 100
$$

where $h_{c}$ and $w_{c}$ are the height and width of the spectrogram slice in pixels, respectively; $n$ is the resolution with respect to each of the color channels of the image; and $p^{i, j}$ are the channel values with respect to $i$ and $j$ pixel in the slice.

The spectrogram resolution allows for a width of 43 pixels for the frequency range of $9-11 \mathrm{kHz}$ and 702 pixels for the entire time interval.

The integral parameter obtained in this way is called the Ionosphere \& Lightning Intention Index (I\&LII).

We note again that according to the above formula and the procedure for calculating the index introduced by us, this integral parameter has three components: R (red), G (green), and B (blue). Below, we analyze the characteristics of this index.

\section{Results}

A visual analysis of data collected over a long period on all the three (R, G, and B) components of the index introduced by us indicated that in the overwhelming majority of cases the change in the $\mathrm{R}$ and G components is cophased and the "behavior" of the $\mathrm{B}$ component is antiphase to the $\mathrm{R}$ component. In the studies described in this paper, we decided to use merely the $\mathrm{R}$ (red) component of our index in view of such a high degree of linear dependence between the components. In the figure captions, this component is denoted as R (I\&LII-R).

Figure 2 shows the dynamics of the $\mathrm{R}$ component of I\&LII from 27 October to 5 November 2017. It should be noted that the time indicated in Figure 2 and in the other figures differs from Moscow time by four hours and corresponds to GMT +7 . One can see that the diurnal variation of the relevant parameter in this figure is clearly expressed.

The observed diurnal variation in this index can be explained with the help of the following two most plausible hypotheses. First, as already mentioned in the Introduction, the source-toreceiver propagation of VLF waves occurs along the ionosphere-Earth "spherical" waveguide [Grudinskaya, 1975 and, accordingly, the propagation conditions of these waves may depend on changes in the state of both ionospheric and terrestrial components of the waveguide. The ionospheric reflectivity is known to enhance at night hours, which leads to an increased reception range of signals of different wavelengths (some of these signals are simply absorbed by the ionospheric $D$-layer in daytime hours).

Figure 3 shows the strength of a $20 \mathrm{kHz}$ signal as a function of the distance to the source and time of day [Cherenkova and Chernyshov, 1984]. It can be seen that at night the intensity of the signal received by the antenna can increase on some paths, regardless of the change in the signal source power up to 4 times.

The fact that during the experiment the level of the VLF signal increased at night in 2.5-4 times in comparison with daytime hours was also confirmed in [Bashkuev et al., 2016.

The regularities described above allow us to claim with reasonable certainty that the diurnal variations in I\&LII observed at the Togagasu station from 27 October to 5 November 2017 occurred due 


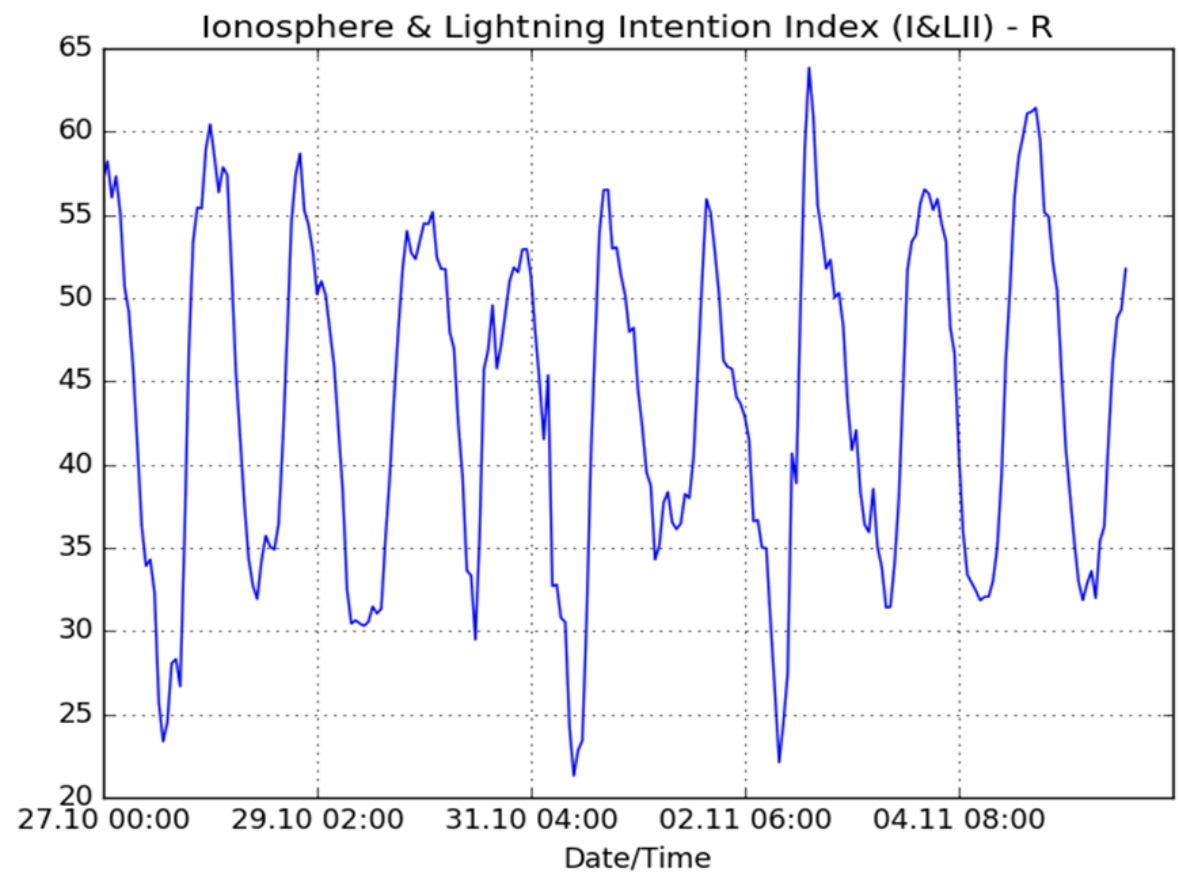

Figure 2. Dynamics of the R component of I\&LII from 27 October 2017 to 5 November 2017.

to diurnal changes in the ionospheric state. However, it would also be feasible to estimate the "contribution" to changes in the I\&LII amplitude not only by changes in the ionospheric state, but also by lightning events occurred at a distance of around $3-5$ thousand kilometers away from the receiving antenna (for the wintertime Northern Hemisphere) if such a "contribution" exists.

The WWLLN international research network provides data on all atmospherics recorded on the
Earth (their coordinates and recording times). According to expert estimates [Hutchins et al., 2012b; Rodger et al., 2006, depending on various conditions and locations, the WWLLN records $10 \%$ to $90 \%$ of the atmospherics appeared during a lightning event. In view of this, it can be assumed that the intensity estimated from a sample of the WWLLN database is proportional to the actual intensity of relevant lightning events. This assumption can well justify the use of WWLLN data for

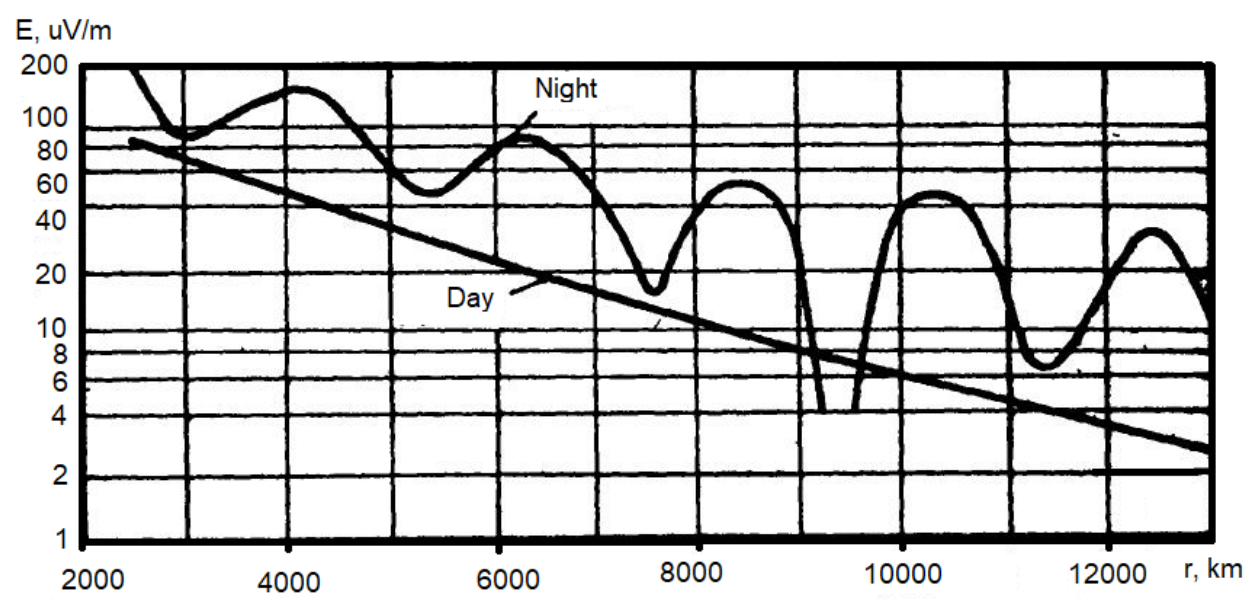

Figure 3. Distribution of daytime and nighttime electric fields at $20 \mathrm{kHz}$. 


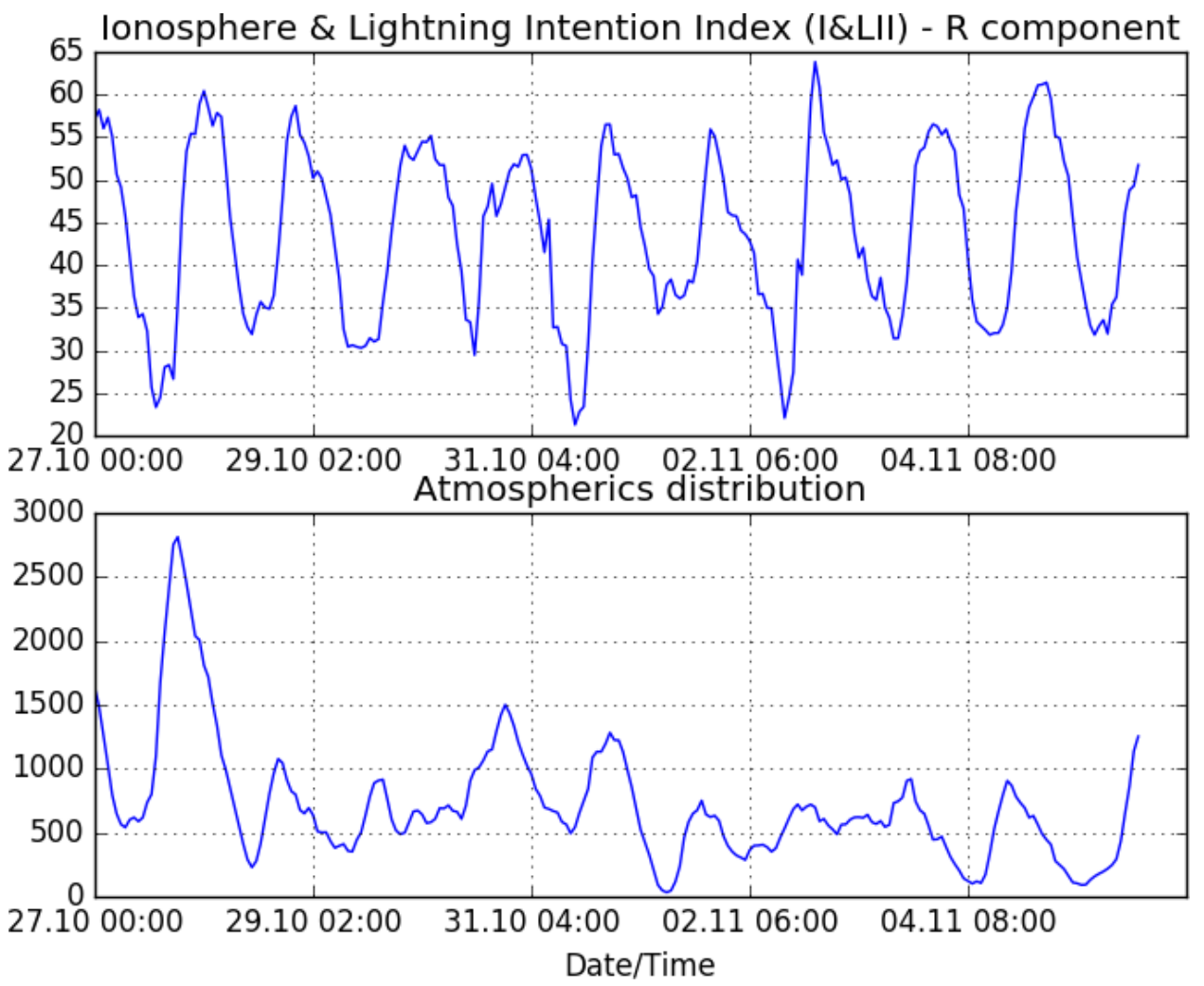

Figure 4. Comparison between I\&LII and hourly distribution of atmospherics for the territory limited by $51^{\circ} \mathrm{N}$ (in the north), $75^{\circ} \mathrm{E}$ (in the west), $105^{\circ} \mathrm{E}$ (in the east), and $5^{\circ} \mathrm{N}$ (in the south) from 27 October 2017 to 5 November 2017.

our case to assess the impact of lightning activity at a distance of $3-5$ thousand kilometers on the I\&LII index formed at the Togagasu station.

For a computational experiment, we took several data samples from the WWLLN database from 10 October 2017 to 11 November 2017. The samples correspond to the areas limited by $51^{\circ} \mathrm{N}$ in the north (Togagasu is located at this parallel), and by $75^{\circ} \mathrm{E}$ and $105^{\circ} \mathrm{E}$ in the west and east, respectively. The influence of solar activity during the daytime can be taken into account if the lightning events considered by us have occurred in the same or neighboring time zones. In the south, the coordinates of the boundary changed in two degrees from $19^{\circ} \mathrm{N}$ to $5^{\circ} \mathrm{N}$. There were a total of eight samples in this study. The intensity of lightning activity in the sample time interval was estimated by the time points, which were calculated along the $Y$-axis by summing the number of atmospherics recorded by the WWLLN during a given hour. For brevity, we will hereafter refer to the total hourly value of this lightning activity index. Considering the sample-covered areas with an approximate ratio of
$111 \mathrm{~km}$ per degree, we can say that we analyzed conditional trapeziums with a large base length of around $3330 \mathrm{~km}$ and a height of 3552 to $5106 \mathrm{~km}$.

The correlation of the time series of the total hourly index of lightning activity constructed for different latitudes with the time series of the I\&LII index (for the same time interval) shows that the maximum correlation for a sample of up to $50^{\circ} \mathrm{N}$ (called "path $5^{\circ}$ ") is only $17.8 \%$. The top panel of Figure 4 shows the time series of I\&LII for 27 October to 5 November 2017, and the time series in the bottom panel shows the total hourly index of lightning activity for "path " for the same time interval.

Estimating the daily correlations, we found that the maximum degree of linear dependence between I\&LII and our estimate for lightning activity as a total hourly index for given areas was observed in the days with mostly nighttime lightning events. For example, the correlation between the two daily time series for "path $7^{\circ}$ " on 28 October 2017 was $79.1 \%$. The top panel of Figure 5 shows the time series of I\&LII for 28 October 2017, and the bottom 


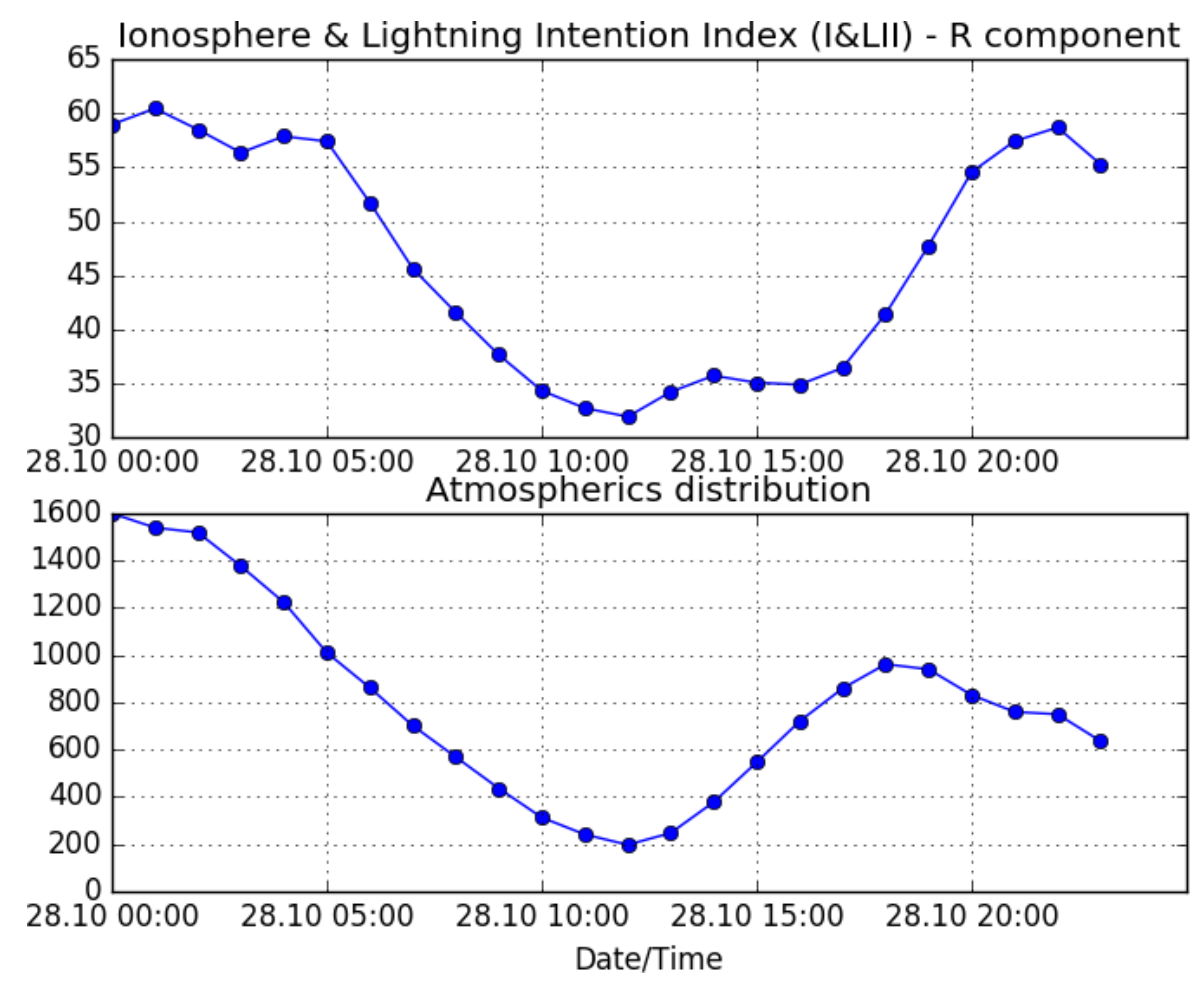

Figure 5. Comparison of well-correlated I\&LII diurnal variations with hourly distribution of atmospherics for the territory limited by $51^{\circ} \mathrm{N}$ (in the north), $75^{\circ} \mathrm{E}$ (in the west), $105^{\circ} \mathrm{E}$ (in the east), and $7^{\circ} \mathrm{N}$ (in the south) on 28 October 2017.

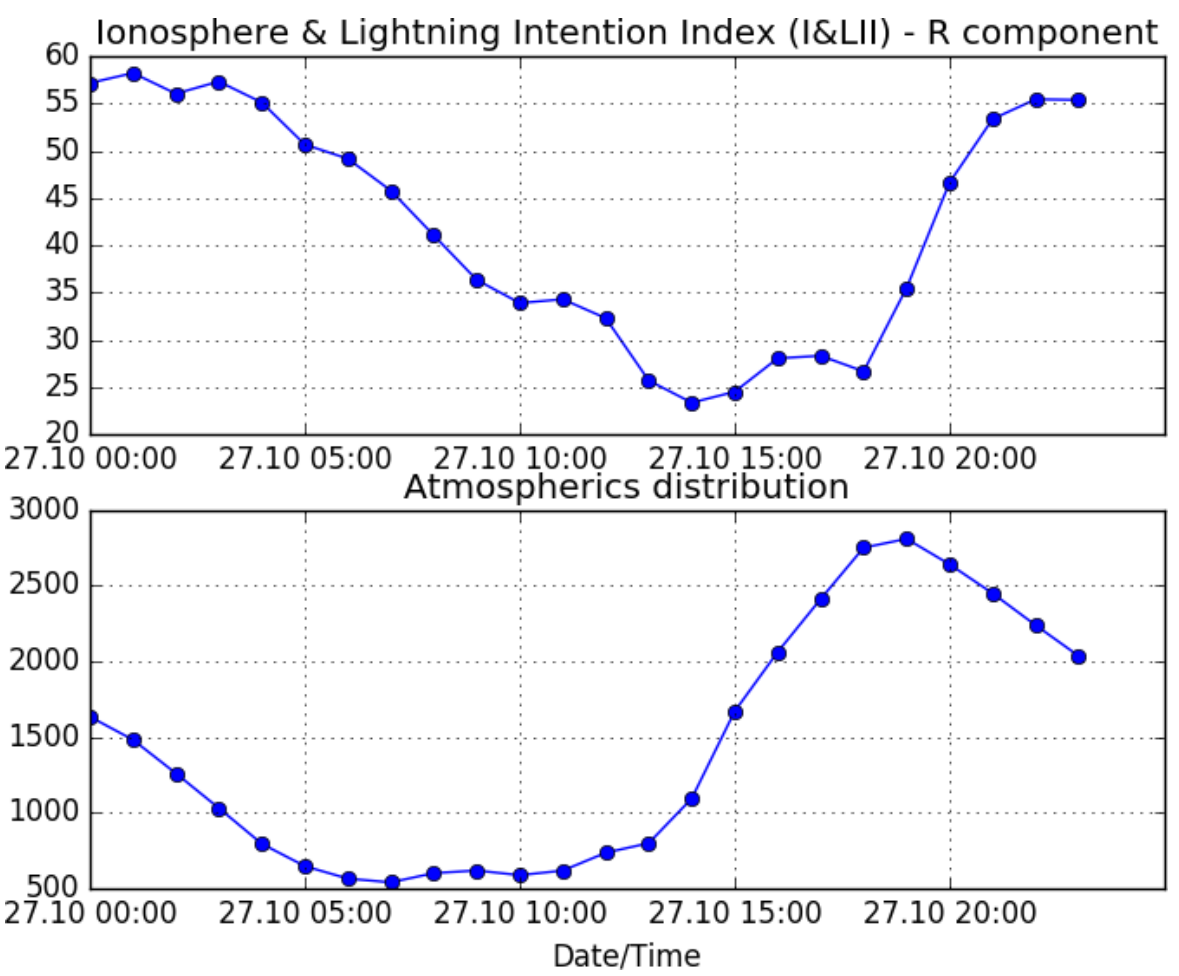

Figure 6. Comparison of ill-correlated I\&LII diurnal variations with hourly distribution of atmospherics for the territory limited by $51^{\circ} \mathrm{N}$ (in the north), $75^{\circ} \mathrm{E}$ (in the west), $105^{\circ} \mathrm{E}$ (in the east), and $5^{\circ} \mathrm{N}$ (in the south) on 27 October 2017. 
Togagasu 2017-10-22
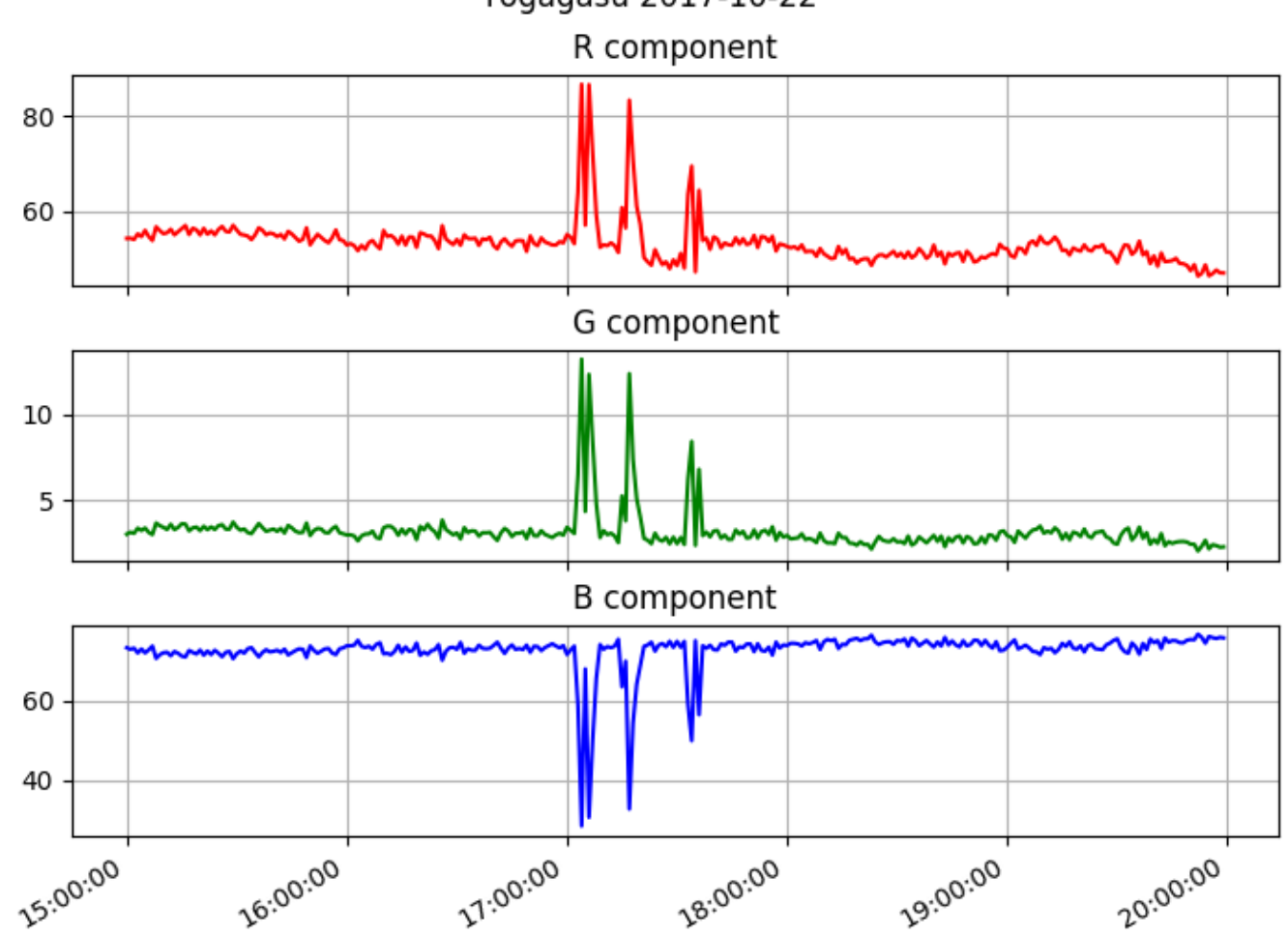

Figure 7. Example of sharp changes in I\&LII, fixing technogenic events on 22 October 2017.

panel shows the time series of the total hourly index of lightning activity for the same day.

The minimum degree of linear dependence between the time series of I\&LII and the time series of the total hourly index of lightning activity was observed in cases when the lightning events occurred during daytime. For example, a correlation of $-3 \%$ was observed for "path $5^{\circ}$ " on 27 October 2017. The top panel of Figure 6 shows the time series of I\&LII for 27 October 2017, and the bottom panel shows the time series of the total hourly lightning activity for "path $5^{\circ}$ " on the same day.

\section{Discussion of Results}

An analysis of the comparative estimates for lightning activity and the I\&LII index considered in this paper allows us to conclude that the I\&LII index has a seasonal character. During the summer, this index can be used to assess the lightning activity in the "near zone", when the level of the signal generated by electromagnetic pulses of lightning discharges exceeds the amplitude of os- cillations caused by diurnal changes in the ionospheric state, affecting the sufficiently weak signals of lightning events of "distant paths". During the winter (with no lightnings in the "near zone"), the I\&LII index can be used both to observe the general ionospheric state and to record "technogenic" events (Figure 7). The word "technogenic" in this context is used and put into quotes because the sources of "outliers" of the time series are unclear. Initially, these "outliers" in observed time series were explained by assuming that the index could be affected by electromagnetic noises from possible welding or similar operations conducted near the installed hardware, which could cause broadband electromagnetic radiation in the local domain. However, the analysis of the time intervals with recorded "outliers", the visual examination of adjacent territories for welding operations, and the deterioration of the well-being of weather-sensitive people concurrently with "outliers" (see below) allowed us to discard the original "noise" hypothesis. We have not managed to fix any existing natural phenomena allowing them to be related to "outliers"; therefore, these observed "events" were named just "technogenic". Some in- 
terest for research can also be presented by the above-mentioned deterioration in the well-being of weather-sensitive people. This deterioration coincides with the observed "outliers". However, since the concurrency of this deterioration and the observed "outliers" was derived from an unrepresentative sample, the large-scale confirmation of the hypothesis requires individual comprehensive research to be arranged and conducted. To be fair, it should also be noted that the sharp changes in the index value, similar to those shown in Figure 7 , are observed non-synchronously at the WWLLN stations currently available for investigations; this allows us to assume that these changes have a local character. In addition, the loss of the antiphase in the "behavior" of the $\mathrm{R}$ and $\mathrm{B}$ components observed at some time intervals is of some interest. It would also be of interest to reveal external factors affecting this. It should be noted that the time series of the integral parameter introduced in this study is equidistant or uniform. The uniformity or invariance of the time step of I\&LII is ensured by the "minute" character of its calculation. Due to the uniformity of the time step, the data processing becomes highly "comfortable" and the errors caused by the interpolation methods that are used to "align" the time in analyzing data with variable time steps can be reduced (the interpolation methods can introduce significant errors into the results).

\section{Conclusions}

In this study, we introduce an integral parameter for estimating the ionospheric and lightning activity (the I\&LII index) and present an algorithm for its calculation that does not require large computational resources and can operate in "real time". The results of studies of some properties of the integral parameter are also presented. Specifically, it has been shown that the variations in I\&LII depend both on the ionospheric state and lightning activity. The observed dependence has both seasonal and diurnal character. In winter and at night, the index is "strongly" affected by the ionospheric state. In summer and at daytime hours, this index can be used to estimate the lightning activity in the "near" zone relative to the observational station. Also, the time series of I\&LII is a series with a fixed time step, which considerably extends the range of mathematical methods that can be used to analyze the results of observations.

Acknowledgments. This study was conducted within the state research target of the Geophysical Center of the Russian Academy of Sciences.

\section{References}

Bashkuev, Yu. B., D. G. Buyanova, V. P. Advokatov, I. B. Naguslaeva (2016), Diurnal variations in VLF radiowaves in inhomogeneous impedance channels, International Journal of Applied Basic Research, No. 11 (part 2), 226-231. (in Russian)

Cherenkova, E. L., $\quad$ O. V. Chernyshev (1984), $R a-$ dio Wave Propagation: Textbook for Higher Education Institutes of Communications, 272 pp. Radio i Svyaz', Moscow. (in Russian)

Dowden, R. L., J. B. Brundell, C. J. Rodger (2002), VLF lightning location by time of group arrival (TOGA) at multiple sites, J. Atm. Sol.-Terr. Phys., 64, 817830, Crossref

Friese, W. (2004), Sfericsempfang, Band 1, Wilhelm Herbst Verlag, Dessau.

Friese, W. (2009), Spezielle Empfangsschaltungen von $50 \mathrm{~Hz}$ bis Mittelwelle, Wilhelm Herbst Verlag, Dessau.

Grudinskaya, G. P. (1975), Radio Wave Propagation, Visshaya Shkola, Moscow. (in Russian)

Hutchins, M. L., R. H. Holzworth, C. J. Rodger, J. B. Brundell (2012a), Far-field power of lightning strokes as measured by the World Wide Lightning Location Network, J. Atm. Ocean. Techn., 29, No. 8, 1102-1110, Crossref

Hutchins, M. L., R. H. Holzworth, J. B. Brundell, C. J. Rodger (2012b), Relative detection efficiency of the World Wide Lightning Location Network, Radio Sci., 47, No. 1, 1-24, Crossref

Kozlov, V. I., V. A. Mullayarov (2004), Lightning Activity in Yakutia, 103 pp. YaB SB RAS, Yakutsk. (in Russian)

Kozlov, V. I., A. Yu. Markova, S. N. Shabaganova (2010), Errors in methods for the observation of lightning discharges by single-point and two-point lightning location systems, Science and Education, No. 1, 7-12. (in Russian)

Rodger, C. J., S. Werner, J. B. Brundell, E. H. Lay, N. R. Thomson, R. H. Holzworth, R. L. Dowden (2006), Detection efficiency of the VLF World-Wide Lightning Location Network (WWLLN): Initial case study, Ann. Geophys., 24, 3197-3214, Crossref

N. G. Kudryavtsev, D. V. Kudin, and E. O. Uchaikin, Gorno-Altaisk State University, Gorno-Altaisk, Russia. (d.kudin@gcras.ru) 